\title{
Role of Li2O2@Li2CO3 Interfaces on Charge Transport in Nonaqueous LiAir Batteries
}

Mekonnen, Yedilfana Setarge; García Lastra, Juan Maria; Hummelshøj, Jens S.; Jin, Chengjun; Vegge, Tejs

Published in:

The Journal of Physical Chemistry Part C

Link to article, DOI:

10.1021/acs.jpcc.5b04432

Publication date:

2015

Document Version

Peer reviewed version

Link back to DTU Orbit

Citation $(A P A)$ : Mekonnen, Y. S., García Lastra, J. M., Hummelshøj, J. S., Jin, C., \& Vegge, T. (2015). Role of Li ${ }_{2} \mathrm{O}_{2} @ \mathrm{Li}_{2} \mathrm{CO}_{3}$
Interfaces on Charge Transport in Nonaqueous LiAir Batteries. The Journal of Physical Chemistry Part C, 119(32), 18066-18073. https://doi.org/10.1021/acs.jpcc.5b04432

\section{General rights}

Copyright and moral rights for the publications made accessible in the public portal are retained by the authors and/or other copyright owners and it is a condition of accessing publications that users recognise and abide by the legal requirements associated with these rights.

- Users may download and print one copy of any publication from the public portal for the purpose of private study or research.

- You may not further distribute the material or use it for any profit-making activity or commercial gain

- You may freely distribute the URL identifying the publication in the public portal 


\title{
The Role of $\mathrm{Li}_{2} \mathrm{O}_{2} @ \mathrm{Li}_{2} \mathrm{CO}_{3}$ Interfaces on Charge Transport in Non-Aqueous Li-Air Batteries
}

Yedilfana S. Mekonnen ${ }^{1}$, Juan M. Garcia-Lastra ${ }^{1}$, Jens S. Hummelshøj ${ }^{3}$, Chengjun $\mathrm{Jin}^{2}$, Tejs Vegge ${ }^{1 *}$

${ }^{1}$ Department of Energy Storage, Technical University of Denmark, Fysikvej, Building 309, 2800 Kgs Lyngby, Denmark

${ }^{2}$ Center for Atomic-scale Materials Design and Department of Physics, Technical University of Denmark, DK2800 Lyngby, Denmark

${ }^{3}$ SUNCAT, SLAC National Accelerator Laboratory, Menlo Park, California 94025, USA

"Corresponding Author E-mail: teve@dtu.dk

\begin{abstract}
The formation and oxidation of the main discharge product in non-aqueous secondary $\mathrm{Li}^{-} \mathrm{O}_{2}$ batteries, i.e. $\mathrm{Li}_{2} \mathrm{O}_{2}$, has been studied intensively, but less attention has been given to the formation of cathode electrolyte interfaces (CEI), which can significantly influence the performance of the $\mathrm{Li}_{-} \mathrm{O}_{2}$ battery. Here, we apply density functional theory with the Hubbard $U$ correction $(D F T+U)$ and non-equilibrium Green's function (NEGF) methods to investigate the role of $\mathrm{Li}_{2} \mathrm{O}_{2} @ \mathrm{Li}_{2} \mathrm{CO}_{3}$ interface layers on the ionic and electronic transport properties at the oxygen electrode. We show that, e.g., lithium vacancies accumulate at the peroxide part of the interface during charge, reducing the coherent electron transport by 2-3 orders of magnitude compared to pristine $\mathrm{Li}_{2} \mathrm{O}_{2}$. During discharge $\mathrm{Li}_{2} \mathrm{O}_{2} @ \mathrm{Li}_{2} \mathrm{CO}_{3}$ interfaces may, however, provide an alternative inplane channel for fast electron polaron hopping that could improve the electronic conductivity and ultimately increase the practical capacity in non-aqueous $\mathrm{Li}^{-} \mathrm{O}_{2}$ batteries.
\end{abstract}

Key words: DFT+U, NEGF, polaron, charge transport, $\mathrm{Li}_{2} \mathrm{O}_{2} @ \mathrm{Li}_{2} \mathrm{CO}_{3}$ interface, conductivity 


\section{Introduction}

Today, most electric vehicles and hybrid electric vehicles rely on Li-ion batteries. The main drawbacks of Li-ion batteries are their high price, slow charging and low energy/power density compared to that of gasoline. ${ }^{1}$ The latest specific energy of Li-ion batteries is $\sim 300 \mathrm{mAh} / \mathrm{g}^{2}$, that is an order of magnitude lower than that of the Li-air battery $\sim 3842 \mathrm{mAh} / \mathrm{g}^{3}$. Recently, metal-air batteries have gained significant attention as a future alternative to Li-ion batteries in the transportation sector. Particularly, the $\mathrm{Li}-\mathrm{O}_{2}$ couple appears a promising choice due to its superior energy storing capacity.

Li-air batteries, however, suffer from several drawbacks that must be resolved before they can enter the market. Various complex chemical and electrochemical side-reactions occur at the interfaces in practical non-aqueous Li-air batteries, which limit the rechargeability and cyclability. ${ }^{4}$ Several kinds of parasitic compounds and interfaces are likely formed between/within the reaction products and cell components in the non-aqueous Li-air batteries. The types of interfaces depend on the type of electrodes and electrolytes used in the cell and the reaction conditions. $\mathrm{Li}_{2} \mathrm{CO}_{3}$ is readily formed at the cathode together with $\mathrm{Li}_{2} \mathrm{O}_{2}$ when carbonate based electrolytes, e.g. ethylene carbonates (EC), are used ${ }^{5,6}$, but if non-carbonate based electrolytes such as dimethoxyethane (DME) is used, $\mathrm{Li}_{2} \mathrm{O}_{2}$ is the main discharge product. In the latter case, layers of $\mathrm{Li}_{2} \mathrm{CO}_{3}$ can also form due to side reaction with the carbon cathode, $\mathrm{DME}$ or $\mathrm{CO}_{2}$ impurities from the air. ${ }^{7,8}$ The discharge capacity in $\mathrm{Li}-\mathrm{O}_{2}$ batteries is primarily limited by the poor electronic conduction in $\mathrm{Li}_{2} \mathrm{O}_{2}{ }^{9}$ and the since electronic conductivity in $\mathrm{Li}_{2} \mathrm{CO}_{3}$ is even smaller than that of $\mathrm{Li}_{2} \mathrm{O}_{2}$, it is critical to determine the effect of such layers. Experiments performed in carbonate or ether based electrolytes reported the evolution of $\mathrm{CO}_{2}$ gas when battery recharges at slightly above $3 \mathrm{~V}$ and 4 $\mathrm{V}$, mainly comes from the electrolyte decomposition and carbonate deposit at the cathode surface, respectively. ${ }^{4}, 6,8,10$ It has also been reported in Li-ion battery studies that, $\mathrm{Li}_{2} \mathrm{CO}_{3}$ is one of the most chemically ${ }^{11}$ and mechanically ${ }^{12}$ stable species formed at both cathode and anode electrodes. Thus, it is inevitably the formation of $\mathrm{Li}_{2} \mathrm{O}_{2} @ \mathrm{Li}_{2} \mathrm{CO}_{3}$ interface in the cathode in non- 
aqueous Li-air batteries at various state of reaction conditions for instance at $\mathrm{Li}_{2} \mathrm{O}_{2} @ \mathrm{C}$ (graphite) and $\mathrm{Li}_{2} \mathrm{O}_{2} @$ @electrolyte interfaces. ${ }^{4}$ To summarize $\mathrm{Li}_{2} \mathrm{O}_{2} @ \mathrm{Li}_{2} \mathrm{CO}_{3}$ interfaces could be formed in different scenarios, namely: a) Liquid Electrolyte $\left|\mathrm{Li}_{2} \mathrm{CO}_{3}\right| \mathrm{Li}_{2} \mathrm{O}_{2} \mid$ Carbon Cathode, which appears when a carbon based electrolyte is used or due to the presence of atmospheric $\mathrm{CO}_{2}$. b) Liquid Electrolyte $\left|\mathrm{Li}_{2} \mathrm{O}_{2}\right| \mathrm{Li}_{2} \mathrm{CO}_{3} \mid$ Carbon Cathode, which has been shown to be formed due to the reactions between the $\mathrm{Li}$ ions and $\mathrm{C}$ cathode in the presence of oxygen. c) Liquid Electrolyte $\left|\mathrm{Li}_{2} \mathrm{CO}_{3}\right| \mathrm{Li}_{2} \mathrm{O}_{2}\left|\mathrm{Li}_{2} \mathrm{CO}_{3}\right|$ Carbon Cathode, which is the combination of scenarios a) and b). We should stress that in the present work we only model the $\mathrm{Li}_{2} \mathrm{O}_{2} @ \mathrm{Li}_{2} \mathrm{CO}_{3}$ interface, disregarding where the interface appears. Thus, our model is valid in the three scenarios mentioned above.

Here, we investigate the implications of $\mathrm{Li}_{2} \mathrm{O}_{2} @ \mathrm{Li}_{2} \mathrm{CO}_{3}$ interfaces for charge transport, i.e. mainly the Lithium diffusion and electronic transport properties in non-aqueous $\mathrm{Li}-\mathrm{O}_{2}$ batteries. ${ }^{13}$ Regarding, the electronic transport we study both polaronic and tunneling conduction regimes. We also show that the $\mathrm{Li}$ vacancies have a thermodynamic driving force for accumulation at the $\mathrm{Li}_{2} \mathrm{O}_{2}$ part of the $\mathrm{Li}_{2} \mathrm{O}_{2} @ \mathrm{Li}_{2} \mathrm{CO}_{3}$ interface compared to pristine $\mathrm{Li}_{2} \mathrm{O}_{2}$. Consequently, we have studied in detail the impact of these $\mathrm{Li}$ vacancies on the coherent transport properties at the interface.

The paper is structured in four major sections. The description of the crystal structures, computational methods and electronic properties of the materials is covered in section 2. In section 3 , the main results and discussions are presented in three subsections. The first subsection (3.1) covers the ionic transport calculations in the materials of interest in non-aqueous Li-air batteries, i.e., $\mathrm{Li}_{2} \mathrm{O}_{2}$, $\mathrm{Li}_{2} \mathrm{CO}_{3}$ and $\mathrm{Li}_{2} \mathrm{O}_{2} @ \mathrm{Li}_{2} \mathrm{CO}_{3}$ interface. The coherent electron transport properties with and without lithium vacancies in $\mathrm{Li}_{2} \mathrm{O}_{2}$ and $\mathrm{Li}_{2} \mathrm{O}_{2} @ \mathrm{Li}_{2} \mathrm{CO}_{3}$ interface is discussed in subsection 3.2, while the polaronic conduction in the $\mathrm{Li}_{2} \mathrm{O}_{2} @ \mathrm{Li}_{2} \mathrm{CO}_{3}$ interface is detailed in subsection 3.3. Finally, we present our main conclusions in section 4. 


\section{Crystal structures and computational methods}

$\mathrm{Li}_{2} \mathrm{O}_{2}$ crystallizes in a hexagonal crystal structure with lattice parameters $a=b=3.187 \AA, c=$ $7.726 \AA$ (space group $P 6_{3} / m m c$, see Figure $1 \mathrm{a}$ ), and it can effectively be viewed as individual peroxide $\mathrm{O}_{2}{ }^{2-}$ ions embedded in sea of $\mathrm{Li}^{+}$ions. ${ }^{14}$ Moreover, in previous DFT calculations it has been reported that the reconstructed (0001), (1100) and (1120) surfaces are the most stable and predominant exposed facets at operating potentials, being about $80 \%$ dominated by (0001) surface. ${ }^{15,16}$

The monoclinic $\mathrm{Li}_{2} \mathrm{CO}_{3}$ crystal structure with space group 15 or $\mathrm{C} 2 / \mathrm{c}$ (see Figure $1 \mathrm{~b}$ ) consists of 4 formula units per unit cell with lattice parameters $a=8.359 \AA, b=4.973 \AA, c=6.197 \AA$ and $\beta=$ $114.83^{\circ} .{ }^{17}$ The planner $\mathrm{CO}_{3}{ }^{-2}$ groups with $\mathrm{C}-\mathrm{O}$ bond lengths of $1.284,1.305$ and $1.305 \AA$ are surrounded by the sea of $\mathrm{Li}^{+}$ions. The $\mathrm{Li}^{+}$and $\mathrm{CO}_{3}{ }^{-2}$ groups are oriented alternatively on the $\mathrm{XY}$ plane. Each $\mathrm{Li}^{+}$ion is coordinated with four oxygens to form a tetrahedral structure.

The $\mathrm{Li}_{2} \mathrm{O}_{2} @ \mathrm{Li}_{2} \mathrm{CO}_{3}$ interface explored in this study is assembled from $\mathrm{Li}_{2} \mathrm{CO}_{3}$ (adopting a two formula unit cell version of a $\mathrm{Li}_{2} \mathrm{CO}_{3}$ crystal structure) and $\mathrm{Li}_{2} \mathrm{O}_{2}$ (adopting a four formula unit cell). The interface is built from a (0001) facet of $\mathrm{Li}_{2} \mathrm{O}_{2}$ and a (011) facet of $\mathrm{Li}_{2} \mathrm{CO}_{3}$ with lattice parameters $a=5.135 \AA, b=6.918 \AA, c=16.165 \AA$. In both components, oxygen terminated surfaces are used. In the $\mathrm{Li}_{2} \mathrm{CO}_{3}$ part of the interface, the planes of the carbonate groups are aligned parallel to the peroxides along the z-axis. The facets are chosen based on their stability and presence in the discharge products: The (0001) facet is one of the most stable and predominant facets (80\%) on $\mathrm{Li}_{2} \mathrm{O}_{2}$ around the equilibrium potential during discharge and charge in non-aqueous Li-air batteries, with an abundant portion of the oxygen rich (0001) surface at potentials suitable for charging. ${ }^{15,}{ }^{16}$, ${ }^{18}$ Moreover, the $\mathrm{Li}_{2} \mathrm{CO}_{3}(011)$ surface is one of the low energy facets ${ }^{19}$ which has an excellent lattice matching with $\mathrm{Li}_{2} \mathrm{O}_{2}(0001)$. As it can be seen in Figure 1c, the two facets match well and form a stable interface within less than $5 \%$ lattice mismatch (the strain is on $\mathrm{Li}_{2} \mathrm{O}_{2}$ ). This constructed interface set-up contains a relatively small number of atoms (the unit cell contains 28 
atoms), which makes the calculations tractable, and at the same time provides a reasonable description of the interface.

Regarding the polarons and Li vacancy migration studies, all the calculations are performed within density functional theory (DFT) ${ }^{20,21}$ as implemented in the GPAW package ${ }^{22,23}$ combined to the atomic simulation environment (ASE) ${ }^{24}$. The package uses a real space grid algorithm based on the projector augmented wave function method ${ }^{25}$ with the frozen core approximation. The Revised Perdew-Burke-Ernzehof (RPBE) exchange correlation functional is used in all calculations ${ }^{26}$. For bulk $\mathrm{Li}_{2} \mathrm{O}_{2}$, we use a $3 \times 3 \times 1$ supercell (72 atoms) with a $3 \times 3 \times 3$ k-point sampling. For bulk $\mathrm{Li}_{2} \mathrm{CO}_{3}$, we employ a $2 \times 2 \times 2$ supercell (192 atoms) with a $1 \times 2 \times 2$ k-point sampling. The calculations of the ionic transport in the $\mathrm{Li}_{2} \mathrm{O}_{2} @ \mathrm{Li}_{2} \mathrm{CO}_{3}$ interface are carried out using the set-up described above (Fig1.c) with 2x2x1 k-point sampling (112 atoms in the supercell) in order to minimize the electrostatic interactions between replicas. Similar supercell size is implemented for the polaronic transport calculations study in the $\mathrm{Li}_{2} \mathrm{O}_{2} @ \mathrm{Li}_{2} \mathrm{CO}_{3}$ interface.

In order to describe properly the localization of polarons using general gradient approximation (GGA) functionals, it has been previously reported that it is necessary to introduce Hubbard corrections to the DFT Hamiltonian. Following previous works in our group we use a $\mathrm{U}=6 \mathrm{eV}$ Hubbard correction applied on the $2 p$ orbitals of carbon and oxygen atoms.

The energy barrier, $E_{b}$, in both the Lithium diffusion and polaronic (hole and electron) hopping is calculated using the climbing image nudged elastic band method (CI-NEB) ${ }^{27,28,29}$. All ground state energies are determined when Hellmann-Feynman forces is less than $0.03 \mathrm{eV} / \AA$. All the atoms in the supercell are free to relax during the optimization. From the computed $E_{b}$, it is possible to obtain the rate $(r)$ and the diffusion coefficient $(D)$ using the relations $r=v e^{-E_{b} / k_{B} T}$ and $D=a^{2} r$, respectively, where $v$ is the hopping rate (in this work we use $v=10^{13} \mathrm{~s}^{-1}$ ) and $a$ is the jump length.

The coherent electronic transport calculations in the tunneling regime are carried out using the Non-equilibrium Green's function (NEGF) formalism. The calculations are performed using a 
localized linear combination of atomic orbitals (LCAO) basis set (double-zeta plus polarization quality basis for all atomic species) as implemented in the Atomistix ToolKit (ATK) ${ }^{30,31,32}$ package, where a central device region (or scattering region) is connected to two semi-infinite leads, which are kept at fixed electronic chemical potentials, $\mu_{\mathrm{L}}$ and $\mu_{R}$, respectively, to simulate an applied bias voltage across the device region given by $V=\left(\mu_{L}-\mu_{R}\right) / e$. The scattering region describing the $\mathrm{Li}_{2} \mathrm{O}_{2} @ \mathrm{Li}_{2} \mathrm{CO}_{3}$ interface contains 4 formula units of $\mathrm{Li}_{2} \mathrm{CO}_{3}$ and 8 formula units of $\mathrm{Li}_{2} \mathrm{O}_{2}$. The electrode regions, i.e. 2 formula units of bulk $\mathrm{Li}_{2} \mathrm{CO}_{3}$ (Left lead) and 4 formula units of $\mathrm{Li}_{2} \mathrm{O}_{2}$ (Right

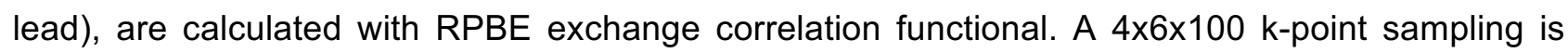
used during the NEGF self-consistent loop. In the finite bias calculations, a positive bias is defined as sending electrons from the left to the right, i.e. in the case of the interface $\mathrm{Li}_{2} \mathrm{CO}_{3}$ is left electrode and $\mathrm{Li}_{2} \mathrm{O}_{2}$ is right electrode, see Figure 2.

\section{Results and Discussions}

Here, the main results and discussions are presented in three subsections as shown below. The first subsection (3.1) covers the ionic transport calculations in the materials of interest in nonaqueous Li-air batteries, i.e., $\mathrm{Li}_{2} \mathrm{O}_{2}, \mathrm{Li}_{2} \mathrm{CO}_{3}$ and $\mathrm{Li}_{2} \mathrm{O}_{2} @ \mathrm{Li}_{2} \mathrm{CO}_{3}$ interface. The coherent electron transport properties with and without lithium vacancies in $\mathrm{Li}_{2} \mathrm{O}_{2}$ and $\mathrm{Li}_{2} \mathrm{O}_{2} @ \mathrm{Li}_{2} \mathrm{CO}_{3}$ interface is discussed in subsection 3.2, while the polaronic conduction in the $\mathrm{Li}_{2} \mathrm{O}_{2} @ \mathrm{Li}_{2} \mathrm{CO}_{3}$ interface is detailed in subsection 3.3.

\subsection{Ionic Transport in $\mathrm{Li}_{2} \mathrm{O}_{2}, \mathrm{Li}_{2} \mathrm{CO}_{3}$ and $\mathrm{Li}_{2} \mathrm{O}_{2} @ \mathrm{Li}_{2} \mathrm{CO}_{3}$ Interface}

In this subsection, the details of the Lithium vacancy diffusion in bulk $\mathrm{Li}_{2} \mathrm{O}_{2}, \mathrm{Li}_{2} \mathrm{CO}_{3}$ and $\mathrm{Li}_{2} \mathrm{O}_{2} @ \mathrm{Li}_{2} \mathrm{CO}_{3}$ interface across various pathways are discussed. Lithium vacancies, $V_{L i}^{0}$, are modeled by removing a single $\mathrm{Li}$ atom from a supercell and subsequently relaxing the system internally. Here, we analyze the effect of neutral vacancies, but positive $\left(V^{+1}{ }_{L i}\right)$ and negatively charged vacancies $\left(V^{-1}{ }_{i}\right)$, can also be present, depending on the potential ${ }^{33}$. For Lithium diffusion studies, a single $\mathrm{Li}$ atom is removed from the corresponding supercells with a total vacancy 
concentration $\left[V_{L i}^{0}\right]$ of $2.78,1.6$ and $2 \%$ in the peroxide, carbonate and interface systems, respectively.

In $\mathrm{Li}_{2} \mathrm{O}_{2}$ there are two possible inequivalent hops in the intralayer direction (in the $\mathrm{XY}$-plane, see Fig.4), namely $B E(X)$ and $A D(X)$ in the $X$ directions and $A F(Y)$ and $B G(Y)$ in the $Y$ directions, being in both cases the energy barriers are close to $1 \mathrm{eV}$. Moreover, interestingly we observe that the hops in $X$ and $Y$ directions within the same intralayer are symmetric (see the overlapped hops in Fig.4). Regarding the interlayer diffusion (in Z direction), there are two possible inequivalent hops, namely $\mathrm{AB}(\mathrm{Z})$ and $\mathrm{BC}(\mathrm{Z})$. We find $E_{b}=0.44 \mathrm{eV}$ and the $E_{b}=0.36 \mathrm{eV}$ for $\mathrm{AB}(\mathrm{Z})$ hop and $\mathrm{BC}(\mathrm{Z})$ hop, respectively, giving an average $E_{b}=0.40 \mathrm{eV}$. Thus it is clear that $V_{L i}^{0}$ diffusion has a preferential channel in Z-direction. The microscopic diffusion channel follows $A \rightarrow B \rightarrow C$ series along the Z-direction with an average rate of $r=2 \times 10^{6} s^{-1}$ and a diffusion coefficient of $\mathrm{D}=$ $1.5 \times 10^{-9} \mathrm{~cm}^{2} / \mathrm{s}$. This relatively small barrier in the $Z$ direction are open the possibility of $V_{L i}^{0}$ diffusion at ambient conditions (for more details see ref. ${ }^{34}$ ).

We have conducted a similar analysis in $\mathrm{Li}_{2} \mathrm{CO}_{3}$, studying five different possible hops (see Fig.5). As it can be seen in Figure 5, the NEB calculations also show a number of minimum energy barrier for a Li vacancy diffusion channels i.e, $\sim 0.2 \mathrm{eV}$ in all the three directions. We found that the $A D$ diffusion path is the most plausible low energy barrier channel in the $\mathrm{Y}$ direction, while $\mathrm{CE}$ diffusion path is in the $Z$ direction and it follows a sequence of diffusion paths in the $X$ direction. For instance, the microscopic diffusion channel along the $X$ direction probably follow $A B$ diffusion path as a first step then followed by $B C$ or $A D$ diffusion path or vice versa $(A D=B C)$. The average rate (r) of $\mathrm{Li}$ vacancy diffusion and diffusion coefficient (D) of $\mathrm{Li}_{2} \mathrm{CO}_{3}$ is equal to $9 x 10^{8} s^{-1}$ and $1.6 \times 10^{-6} \mathrm{~cm}^{2} / \mathrm{s}$, respectively.

The formation energies of $V_{L i}^{0}$ vacancies in $\mathrm{Li}_{2} \mathrm{O}_{2}$ bulk and $\mathrm{Li}_{2} \mathrm{CO}_{3}$ bulk are $3.00 \mathrm{eV}$ and 4.20 $\mathrm{eV}$, respectively, whereas the formation energies of $V_{L i}^{0}$ vacancies at the $\mathrm{Li}_{2} \mathrm{O}_{2} @ \mathrm{Li}_{2} \mathrm{CO}_{3}$ interface are $2.71 \mathrm{eV}$ in the $\mathrm{Li}_{2} \mathrm{O}_{2}$ part of the interface and $3.24 \mathrm{eV}$ in the $\mathrm{Li}_{2} \mathrm{CO}_{3}$ part. This means that in both materials vacancies will accumulate at the $\mathrm{Li}_{2} \mathrm{O}_{2} @ \mathrm{Li}_{2} \mathrm{CO}_{3}$ interface rather than in their 
respective bulk. We have also calculated that there is no barrier to move $V_{L i}^{0}$ vacancies from the $\mathrm{Li}_{2} \mathrm{CO}_{3}$ part of the interface to the $\mathrm{Li}_{2} \mathrm{O}_{2}$ at a neutral background charge, suggesting that $V_{L i}^{O}$ vacancies will tend to pile in the latter. This also implies that the presence of the interface will not cause the ionic conductivity to become rate limiting under practical operating conditions in $\mathrm{Li}^{-\mathrm{O}_{2}}$ batteries.

\subsection{Coherent Electron Transport in $\mathrm{Li}_{2} \mathrm{O}_{2}$ and $\mathrm{Li}_{2} \mathrm{O}_{2} @ \mathrm{Li}_{2} \mathrm{CO}_{3}$ Interface}

In order to have a comprehensive understanding of the coherent electron transport at the $\mathrm{Li}_{2} \mathrm{O}_{2} @ \mathrm{Li}_{2} \mathrm{CO}_{3}$ interface it is instructive to examine the density of states (DOS) of $\mathrm{Li}_{2} \mathrm{O}_{2}$ and $\mathrm{Li}_{2} \mathrm{CO}_{3}$ bulks and compare them with the one of the interface. In Fig. 3, we can see that both $\mathrm{Li}_{2} \mathrm{O}_{2}$ and $\mathrm{Li}_{2} \mathrm{CO}_{3}$ are both wide bandgap insulators with calculated band gaps (using $\mathrm{RPBE}+\mathrm{U}$ functional with $\mathrm{U}=6 \mathrm{eV}$ ) of $5.03 \mathrm{eV}$ for $\mathrm{Li}_{2} \mathrm{O}_{2}$ and $8.01 \mathrm{eV}$ for $\mathrm{Li}_{2} \mathrm{CO}_{3}$. The $\mathrm{Li}_{2} \mathrm{O}_{2} @ \mathrm{Li}_{2} \mathrm{CO}_{3}$ interface shows a $4.82 \mathrm{eV}$ band gap (very close to the one of pristine $\mathrm{Li}_{2} \mathrm{O}_{2}$ bulk) and it can be viewed as the superposition of individual DOS of the $\mathrm{Li}_{2} \mathrm{O}_{2}$ and $\mathrm{Li}_{2} \mathrm{CO}_{3}$, with no presence of mid-gap interface states. In this situation it is expected that for bias voltages (negative or positive) around 2-2.5 eV (i.e. half of the bandgap of $\mathrm{Li}_{2} \mathrm{O}_{2}$ ) we will start to see a relative good conductance in $\mathrm{Li}_{2} \mathrm{O}_{2}$ bulk. However, for the same bias we will expect a drastic drop in the conductance at the $\mathrm{Li}_{2} \mathrm{O}_{2} @ \mathrm{Li}_{2} \mathrm{CO}_{3}$ interface since there are no $\mathrm{Li}_{2} \mathrm{CO}_{3}$ levels at these energies.

Regarding the presence of vacancies in $\mathrm{Li}_{2} \mathrm{O}_{2}$ bulk and at the $\mathrm{Li}_{2} \mathrm{O}_{2} @ \mathrm{Li}_{2} \mathrm{CO}_{3}$ interface (vacancies are located at the $\mathrm{Li}_{2} \mathrm{O}_{2}$ part of the interface, following the results in subsection 3.1), the DOS of both defect systems reveals that the vacancy levels pin the Fermi level of the pristine systems. This implies that $V_{L i}^{0}$ vacancies are not going to open new electron tunneling channels in these systems and they are going to have a detrimental effect in the conductivity due to their action as scattering centers.

In order to check the plausibility of these assumptions we perform DFT-NEGF calculations as described in section 2. We can see in Fig. 7a significant current (around to $10 \mathrm{~mA} / \mathrm{cm}^{2}$ ) begins to show up just around $\pm 2.0 \mathrm{~V}$ in pristine $\mathrm{Li}_{2} \mathrm{O}_{2}$ bulk. However, at the interface current start rising at 
higher potentials (above $\pm 3.80 \mathrm{~V}$ ), due to the wider gap of $\mathrm{Li}_{2} \mathrm{CO}_{3}$, and currents are also reduced three orders of magnitude with respect to the ones in $\mathrm{Li}_{2} \mathrm{O}_{2}$ bulk. Furthermore $V_{L i}^{0}$ vacancies reduce the currents at relevant voltages, of both $\mathrm{Li}_{2} \mathrm{O}_{2}$ bulk and $\mathrm{Li}_{2} \mathrm{O}_{2} @ \mathrm{Li}_{2} \mathrm{CO}_{3}$ interface, by a factor of 2. Summarizing, we can conclude that the presence of $\mathrm{Li}_{2} \mathrm{O}_{2} @ \mathrm{Li}_{2} \mathrm{CO}_{3}$ interfaces and $V_{L i}$ vacancies in $\mathrm{Li}_{2} \mathrm{O}_{2}$ has a substantial negative effect, on the coherent electronic transport at the oxygen electrode of $\mathrm{Li}_{-} \mathrm{O}_{2}$ batteries.

\subsection{Polaronic Transport in $\mathrm{Li}_{2} \mathrm{O}_{2} @ \mathrm{Li}_{2} \mathrm{CO}_{3}$ Interface}

We have already reported that both $\mathrm{Li}_{2} \mathrm{O}_{2}$ and $\mathrm{Li}_{2} \mathrm{CO}_{3}$ bulks can hold hole polarons with sufficiently low migration barriers $(0.39 \mathrm{eV}$ for the former and $0.55 \mathrm{eV}$ for the latter) to become an alternative path for electronic transport. ${ }^{35}$ We also found that both materials can hold excess electron polarons. However, the migration barriers for electron polarons are much higher than the ones of hole polarons (1.408 eV in $\mathrm{Li}_{2} \mathrm{O}_{2}$ and 1.05 in $\left.\mathrm{Li}_{2} \mathrm{CO}_{3}\right)$. Here, we will focus on polaronic conduction (for both holes and excess electrons) at the $\mathrm{Li}_{2} \mathrm{O}_{2} @ \mathrm{Li}_{2} \mathrm{CO}_{3}$ interface.

When we consider polaron localization at the $\mathrm{Li}_{2} \mathrm{O}_{2}$ part of the interface we observe that the hole (excess electron) polaron is localized by shortening (stretching) the bond length of one of the O-O peroxide bond from 1.55 to $1.33 \AA(2.45 \AA)$. The localization can also take place at the $\mathrm{Li}_{2} \mathrm{CO}_{3}$ part of the interface. In this case the hole (excess electron) is localized in one of the carbonate ions which shortens (stretches) its $\mathrm{C}-\mathrm{O}$ bond lengths from an average of $1.31 \AA$ to an average of $1.23 \AA(1.35 \AA)$. Apart from the geometry distortions we observe in all the cases the appearance of a magnetic moment in the oxyanions, which is another footprint of the hole (excess electron) localization. These localized states are more stable than the delocalized ones and particularly the electron polaron is found to be strongly localized, i.e. by more than $2 \mathrm{eV}$ relative to the delocalized state (see Table 1). All these features are very similar to the ones we found for $\mathrm{Li}_{2} \mathrm{O}_{2}$ and $\mathrm{Li}_{2} \mathrm{CO}_{3}$ bulks. ${ }^{35}$ 
It is interesting to notice that hole polarons are more stable in the $\mathrm{Li}_{2} \mathrm{O}_{2}$ part of the $\mathrm{Li}_{2} \mathrm{O}_{2} @ \mathrm{Li}_{2} \mathrm{CO}_{3}$ interface by $0.83 \mathrm{eV}$, whereas the excess electron polarons are more stable in the $\mathrm{Li}_{2} \mathrm{CO}_{3}$ part by $0.10 \mathrm{eV}$ (see Table 1 and Fig. 9). This is due to the different magnitude of the distortions in the peroxide ions of $\mathrm{Li}_{2} \mathrm{O}_{2}$, i.e. a hole localized in a peroxide ion involves a change in the O-O bonding distance of $0.2 \AA$, while the localization of an excess electron requires stretching the bonding by $0.9 \AA$.

Accordingly to the NEB calculations, the energy barriers for the polaronic transport of excess electrons across the interface (see direction $z$ in Fig. 9) are very similar to the ones observed in $\mathrm{Li}_{2} \mathrm{O}_{2}$ and $\mathrm{Li}_{2} \mathrm{CO}_{3}$ bulks. The barrier for transporting excess electron polarons from $\mathrm{Li}_{2} \mathrm{O}_{2}$ to $\mathrm{Li}_{2} \mathrm{CO}_{3}$ is $1.39 \mathrm{eV}$ (and $1.48 \mathrm{eV}$ from $\mathrm{Li}_{2} \mathrm{CO}_{3}$ to $\mathrm{Li}_{2} \mathrm{O}_{2}$ ), very close to the $1.41 \mathrm{eV}$ in $\mathrm{Li}_{2} \mathrm{O}_{2}$ bulk and $1.05 \mathrm{in}$ $\mathrm{Li}_{2} \mathrm{CO}_{3}$ bulk. This implies that the excess electron polaronic transport across $\mathrm{Li}_{2} \mathrm{O}_{2} @ \mathrm{Li}_{2} \mathrm{CO}_{3}$ interfaces is an inaccessible channel for electronic transport. The polaron hopping barrier for holes is much more asymmetric: the barrier for the hop from $\mathrm{Li}_{2} \mathrm{CO}_{3}$ to $\mathrm{Li}_{2} \mathrm{O}_{2}$ to is $0.4 \mathrm{eV}$ (in $\mathrm{Li}_{2} \mathrm{O}_{2}$ bulk is $0.39 \mathrm{eV}$ ), while it is $1.3 \mathrm{eV}$ in the opposite direction. In this scenario we can conclude that $\mathrm{Li}_{2} \mathrm{O}_{2} @ \mathrm{Li}_{2} \mathrm{CO}_{3}$ interfaces act like a diode, which allows hole polaronic transport only from the $\mathrm{Li}_{2} \mathrm{CO}_{3}$ part of the interface to the $\mathrm{Li}_{2} \mathrm{O}_{2}$ one.

Regarding the polaronic transport parallel to the $\mathrm{Li}_{2} \mathrm{O}_{2} @ \mathrm{Li}_{2} \mathrm{CO}_{3}$ interface we observe that an alternative channel for electron polaron hopping opens within the peroxide part of the interface (intralayer in the $\mathrm{X}$ and $\mathrm{Y}$ directions in Fig. 9) with a low hopping barrier of less than $0.5 \mathrm{eV}$, providing an improved conduction channel compared to bulk $\mathrm{Li}_{2} \mathrm{O}_{2}$. The corresponding rates $(r)$ in $X$ and $Y$ intralayer electron polaron hopping are found to be $5 \times 10^{5} \mathrm{~s}^{-1}$ and $9 \times 10^{7} \mathrm{~s}^{-1}$ with the diffusion coefficients of $5 \times 10^{-10} \mathrm{~cm}^{2} / \mathrm{s}$ and $1 \times 10^{-7} \mathrm{~cm}^{2} / \mathrm{s}$, respectively. Unlike what is observed for bulk $\mathrm{Li}_{2} \mathrm{O}_{2}$, the hole polaron hopping barriers in the $\mathrm{Li}_{2} \mathrm{O}_{2} @ \mathrm{Li}_{2} \mathrm{CO}_{3}$ interface are significantly larger compared to the low barriers reported for $\mathrm{Li}_{2} \mathrm{O}_{2}$ by Garcia, et al ${ }^{35}$. On the other hand, the intralayer hole polaron hopping at the $\mathrm{Li}_{2} \mathrm{O}_{2} @ \mathrm{Li}_{2} \mathrm{CO}_{3}$ interface is quite limited in comparison with that of $\mathrm{Li}_{2} \mathrm{O}_{2}$ bulk (the barriers at the interface are at least twice larger than in $\mathrm{Li}_{2} \mathrm{O}_{2}$ bulk). 


\section{Conclusions}

The detailed understanding of charge carrier transport across the $\mathrm{Li}_{2} \mathrm{O}_{2} @ \mathrm{Li}_{2} \mathrm{CO}_{3}$ interfaces can shed new light on the limited performance of non-aqueous $\mathrm{Li}^{-} \mathrm{O}_{2}$ batteries. DFT+U and NEGF's calculations have been applied to study the neutral lithium vacancy and electron/hole polaron migration barriers and I/ $\mathrm{V}$ curves of the $\mathrm{Li}_{2} \mathrm{O}_{2}$ and $\mathrm{Li}_{2} \mathrm{O}_{2} @ \mathrm{Li}_{2} \mathrm{CO}_{3}$ interface with and without defects. The role of Li vacancies in the cycling process is investigated and found to be prone to trapping at the peroxide part of the interface based on the relative vacancy formation energies, resulting in substantial reduction in the coherent transport. According to NEB calculations, the Li vacancy diffusion revealed low energy barriers in the plane of the interface (intralayer in XY plane) and across the interface (interlayer) within the carbonates as well as peroxides. Remarkably, low electron polaron hopping barriers are revealed in the plane of the interface in both $X$ and $Y$ directions and likely opens alternative conduction pathways when there is sufficient electron polarons concentration near the interface. However, the hole polaron conduction seems to be limited at the interface compared to values obtained for $\mathrm{Li}_{2} \mathrm{O}_{2} \cdot{ }^{35}$ The coherent electron transport calculations showed a lithium vacancy at the interface reduces the accessible current densities. It is also possible to conclude that the coherent transport is reduced due to the interfaces and defects. However, the electron polaron conduction is likely improved at the plane of the $\mathrm{Li}_{2} \mathrm{O}_{2} @ \mathrm{Li}_{2} \mathrm{CO}_{3}$ interfaces. We are currently conducting experimental work to explore the possibility of creating such interfaces but could be difficult to make the desired interface experimentally. Nevertheless, this property could be exploited to design a nanostructured cathode with improved conductivity, e.g. carbon nanotubes (CNT) growth on graphene could be used as a cathode (this has been already done in Li-ion battery anode ${ }^{36}$ ) where $\mathrm{Li}_{2} \mathrm{CO}_{3}$ could spontaneously coated the nanotubes. Subsequently, the space in between the nanotubes could be filled by $\mathrm{Li}_{2} \mathrm{O}_{2}$ during discharge; giving rise to $\mathrm{Li}_{2} \mathrm{O}_{2} @ \mathrm{Li}_{2} \mathrm{CO}_{3}$ interfaces." 


\section{Acknowledgements}

The authors acknowledge support of this work from the ReLiable project (Project No. 11116792) funded by the Danish Council for Strategic Research Programme Commission on Sustainable Energy and Environment. JMGL acknowledges support from the Spanish Ministry of Economy and Competitiveness under Projects FIS2012-30996 and FIS2010-21282-C02-01 and from the Mat4Bat project founded by Villum Foundation Young Investigators Program (Project No. 10096). We also would like to thank Prof. Alan C. Luntz and Dr. Umberto M. Pozzoni for the constructive discussions we had.

\section{References}

(1) Tarascon, J. M.; Armand, M. Issues and Challenges Facing Rechargeable Lithium Batteries. Nature 2001, 414, 359-367.

(2) Armand, M.; Tarascon, J. M. Building Better Batteries. Nature 2008, 451, 652-657.

(3) Balaish, M.; Kraytsberg, A.; Ein-Eli, Y. A Critical Review on Lithium-Air Battery Electrolytes. Phys. Chem. Chem. Phys. 2014, 16, 2801-2822.

(4) Mccloskey, B. D.; Speidel, A.; Scheffler, R.; Miller, D. C.; Viswanathan, V.; Hummelshøj, J. S.; Nørskov, J. K.; Luntz, A. C. Twin Problems of Interfacial Carbonate Formation in Nonaqueous. J. Phys. Chem. Lett. 2012, 3, 997-1001.

(5) Younesi, R.; Hahlin, M.; Bjorefors, F.; Johansson, P.; Edstrom, K. Li-O2 Battery Degradation by Lithium Peroxide (Li2O2): A Model Study. Chem. Mater. 2013.

(6) Xu, W.; Hu, J.; Engelhard, M. H.; Towne, S. A.; Hardy, J. S.; Xiao, J.; Feng, J.; Hu, M. Y.; Zhang, J.; Ding, F.; et al. The Stability of Organic Solvents and Carbon Electrode in Nonaqueous Li-O2 Batteries. J. Power Sources 2012, 215, 240-247.

(7) Viswanathan, V.; Thygesen, K. S.; Hummelshøj, J. S.; Nørskov, J. K.; Girishkumar, G.; McCloskey, B. D.; Luntz, A. C. Electrical Conductivity in Li2O2 and Its Role in Determining Capacity Limitations in Non-Aqueous Li-O2 Batteries. J. Chem. Phys. 2011, 135, 214704.

(8) Mekonnen, Y. S.; Knudsen, K. B.; Mýrdal, J. S. G.; Younesi, R.; Højberg, J.; Hjelm, J.; Norby, P.; Vegge, T. Communication: The Influence of CO2 Poisoning on Overvoltages and Discharge Capacity in Non-Aqueous Li-Air Batteries. J. Chem. Phys. 2014, 140, 121101.

(9) Højberg, J.; McCloskey, B. D.; Hjelm, J.; Vegge, T.; Johansen, K.; Norby, P.; Luntz, A. C. An Electrochemical Impedance Spectroscopy Investigation of the Overpotentials in Li-O 2 Batteries. ACS Appl. Mater. Interfaces 2015, 7, 4039-4047. 
(10) Albertus, P.; Girishkumar, G.; McCloskey, B.; Sánchez-Carrera, R. S.; Kozinsky, B.; Christensen, J.; Luntz, A. C. Identifying Capacity Limitations in the Li/Oxygen Battery Using Experiments and Modeling. J. Electrochem. Soc. 2011, 158, A343-A351.

(11) Shi, S.; Qi, Y.; Li, H.; Hector, L. G. Defect Thermodynamics and Diffusion Mechanisms in $\mathrm{Li} 2 \mathrm{CO} 3$ and Implications for the Solid Electrolyte Interphase in Li-lon Batteries. J. Phys. Chem. C 2013, 117, 8579-8593.

(12) Fracassi, P. F.; Klein, M. L.; Della Valle, R. G. Lattice Dynamics of Ionic Molecular Crystals in the Rigid Ion Approximation, Phases II and III of Sodium Superoxide '. Canada J. Phys. 1984, 62, 54-64.

(13) Chen, J.; Hummelshøj, J. S.; Thygesen, K. S.; Myrdal, J. S. G.; Nørskov, J. K.; Vegge, T. The Role of Transition Metal Interfaces on the Electronic Transport in Lithium-air Batteries. Catal. Today 2011, 165, 2-9.

(14) Cota, L. G.; De La Mora, P. On the Structure of Lithium Peroxide, Li2O2. Acta Crystallogr. 2005, B61, 133-136.

(15) Radin, M. D.; Tian, F.; Siegel, D. J. Electronic Structure of Li2O2 \{0001\} Surfaces. J. Mater. Sci. 2012, 47, 7564-7570.

(16) Hummelshøj, J. S.; Luntz, a C.; Nørskov, J. K. Theoretical Evidence for Low Kinetic Overpotentials in Li-O2 Electrochemistry. J. Chem. Phys. 2013, 138, 034703.

(17) Effenberger, H.; Zemann, J. Refining the Crystal-Structure of Lithium-Carbonate, LI2CO3. Z. Kristallogr. 1979, 150, 133-138.

(18) Mo, Y.; Ong, S. P.; Ceder, G. First-Principles Study of the Oxygen Evolution Reaction of Lithium Peroxide in the Lithium-Air Battery. Phys. Rev. B - Condens. Matter Mater. Phys. 2011, 84, 205446.

(19) Bruno, M.; Prencipe, M. Ab Initio Quantum-Mechanical Modeling of the (001), and (110) Surfaces of Zabuyelite (Li2CO3). Surf. Sci. 2007, 601, 3012-3019.

(20) Ernzerhof, M.; Scuseria, G. E. Perspective on "Inhomogeneous Electron Gas." Theor. Chem. Acc. 2000, 103, 259-262.

(21) W. Kohn and L. J. Sham. Self-Consistent Equation Including Exchange and Correlation Effects. Phys. Rev. 1965, 140, A 1133 - A 1138.

(22) Mortensen, J. J.; Hansen, L. B.; Jacobsen, K. W. A Real-Space Grid Implementation of the Projector Augmented Wave Method. Phys. Rev. B 2005, 71, 035109.

(23) Enkovaara, J.; Rostgaard, C.; Mortensen, J. J.; Chen, J.; Dułak, M.; Ferrighi, L.; Gavnholt, J.; Glinsvad, C.; Haikola, V.; Hansen, H. a; et al. Electronic Structure Calculations with GPAW: A Real-Space Implementation of the Projector Augmented-Wave Method. J. Phys. Condens. Matter 2010, 22, 253202.

(24) Bahn, S. R.; Jaconsen, K. W. An Object-Oriented Scripting Interface to a Legacy Electronic Strcture Code. Comput. Sci. Eng. 2002, 4, 56-66. 
(25) Blochl, P. E. Projected Augmented-Wave Method. Phys. Rev. B 1994, 50, 17953-17979.

(26) Hammer, B.; Hansen, L.; Nørskov, J. Improved Adsorption Energetics within DensityFunctional Theory Using Revised Perdew-Burke-Ernzerhof Functionals. Phys. Rev. B 1999, $59,7413-7421$.

(27) Henkelman, G.; Jonsson, H. Improved Tangent Estimate in the Nudged Elastic Band Method for Finding Minimum Energy Paths and Saddle Points. J. Chem. Phys. 2000, 113, 9978-9985.

(28) Hanggi, P.; Talkner, P.; Borkovec, M. Reaction-Rate Theory: Fifty Years after Kramers. Rev. Mod. Phys. 1990, 62, 251-342.

(29) Vegge, T.; Rasmussen, T.; Leffers, T.; Pedersen, O.; Jacobsen, K. Determination of the of Rate Cross Slip of Screw Dislocations. Phys. Rev. Lett. 2000, 85, 3866-3869.

(30) Atomistix ToolKit version 2014.1, QuantumWise A/S (www.quantumwise.com).

(31) Brandbyge, M.; Mozos, J.-L.; Ordejón, P.; Taylor, J.; Stokbro, K. Density-Functional Method for Nonequilibrium Electron Transport. Phys. Rev. B 2002, 65, 165401.

(32) Soler, J. M.; Artacho, E.; Gale, J. D.; Garcia, A.; Junquera, J.; Ordejon, P.; Sanchez-Portal, D. The SIESTA Method for Ab Initio Order-N Materials Simulation. J. Phys. Condens. Matter 2002, 14, 2745-2779.

(33) Varley, J. B.; Viswanathan, V.; Nørskov, J. K.; Luntz, a. C. Lithium and Oxygen Vacancies and Their Role in Li2O2 Charge Transport in Li-O2 Batteries. Energy Environ. Sci. 2014, 7, 720-727.

(34) Radin, M. D.; Siegel, D. J. Charge Transport in Lithium Peroxide: Relevance for Rechargeable Metal-air Batteries. Energy Environ. Sci. 2013, 6, 2370-2379.

(35) Garcia-Lastra, J. M.; Myrdal, J. S. G.; Christensen, R.; Thygesen, K. S.; Vegge, T. DFT+U Study of Polaronic Conduction in Li2O2 and Li2CO3 : Implications for Li-Air Batteries. J. Phys. Chem. C 2013, 117, 5568-5577.

(36) Wang, W.; Ruiz, I.; Guo, S.; Favors, Z.; Bay, H. H.; Ozkan, M.; Ozkan, C. S. Hybrid Carbon Nanotube and Graphene Nanostructures for Lithium Ion Battery Anodes. Nano Energy 2014, 3, 113-118. 


\section{Tables}

Table 1. Energy difference between the localized (polaron)and delocalized states $\left(\Delta \mathrm{E}_{\text {loc-del }}\right)$ in eV for the $\mathrm{Li}_{2} \mathrm{O}_{2} @ \mathrm{Li}_{2} \mathrm{CO}_{3}$ interface. The hole and excess electron are localized at the $\mathrm{Li}_{2} \mathrm{O}_{2}$ and $\mathrm{Li}_{2} \mathrm{CO}_{3}$ parts of the interface using RPBE and RPBE $+U(\mathrm{U}=6 \mathrm{eV})$, as shown in Table 1.

\begin{tabular}{ccccc}
\hline Method & $\begin{array}{c}\text { Hole polaron } \\
\text { in the } \\
\mathrm{Li}_{2} \mathrm{O}_{2} \text { part }\end{array}$ & $\begin{array}{c}\text { Hole polaron in } \\
\text { the } \mathrm{Li}_{2} \mathrm{CO}_{3} \text { part }\end{array}$ & $\begin{array}{c}\text { Electron } \\
\text { polaron in the } \\
\mathrm{Li}_{2} \mathrm{O}_{2} \text { part }\end{array}$ & $\begin{array}{c}\text { Electron polaron } \\
\text { in the } \mathrm{Li}_{2} \mathrm{CO}_{3} \\
\text { part }\end{array}$ \\
\hline $\begin{array}{c}\text { RPBE } \\
\text { delocalized }\end{array}$ & delocalized & delocalized & Delocalized \\
$(\mathrm{U}=6)$ & -1.40 & $-0,57$ & -2.57 & -2.67 \\
\hline
\end{tabular}

\section{Figure Captions}

Figure 1. (a) Hexagonal $\mathrm{Li}_{2} \mathrm{O}_{2}$ structure with lattice parameters $a=b=3.187 \AA, c=7.726 \AA$ (space group $\mathrm{P}_{3} / \mathrm{mmc}$ ). (b) Monoclinic $\mathrm{Li}_{2} \mathrm{CO}_{3}$ structure with space group $15(\mathrm{C} 2 / \mathrm{c})$ with lattice parameters $a=8.359 \AA, b=4.973 \AA, c=6.197 \AA$ and $b=114.83^{\circ}$. (c) An interface, $\mathrm{Li}_{2} \mathrm{O}_{2} @ \mathrm{Li}_{2} \mathrm{CO}_{3}$, with $4.8 \%$ strains on $\mathrm{Li}_{2} \mathrm{O}_{2}$.

Figure 2. Structural setup for the device region for the pristine interface $\mathrm{Li}_{2} \mathrm{O}_{2} @ \mathrm{Li}_{2} \mathrm{CO}_{3}$ (upper), and with a Li-vacancy at the peroxide part of the interface, $\mathrm{Li}_{2} \mathrm{O}_{2}$ vac@ $\mathrm{Li}_{2} \mathrm{CO}_{3}$ (lower).

Figure 3. The total density of states (DOS) relative to the Fermi energy for a) pristine $\mathrm{Li}_{2} \mathrm{O}_{2}$, $\mathrm{Li}_{2} \mathrm{CO}_{3}$ and $\mathrm{Li}_{2} \mathrm{O}_{2} @ \mathrm{Li}_{2} \mathrm{CO}_{3}$ and b) pristine $\mathrm{Li}_{2} \mathrm{O}_{2} @ \mathrm{Li}_{2} \mathrm{CO}_{3}$ and with a defect (neutral Li-vacancy, $V_{L i}^{0}$ ) at the peroxide part of the interface $\mathrm{Li}_{2} \mathrm{O}_{2} \mathrm{Vac} @ \mathrm{Li}_{2} \mathrm{CO}_{3}$ is obtained using RPBE + U $(\mathrm{U}=6 \mathrm{eV})$. 
Figure 4. The calculated NEB paths for migration of neutral Li-vacancies, $V_{L i}^{0}$, following various diffusion paths in bulk $\mathrm{Li}_{2} \mathrm{O}_{2}$ using a $3 \times 3 \times 1$ supercell. The minimum barrier is found to be $0.36 \mathrm{eV}$.

Figure 5. Calculated NEB paths for Li vacancy $\left(V_{L i}^{0}\right)$ diffusion in bulk $\mathrm{Li}_{2} \mathrm{CO}_{3}$ along different channels. A minimum energy barrier is obtained about $0.20 \mathrm{eV}$.

Figure 6. NEB calculations for the Li vacancy diffusion barrier at the $\mathrm{Li}_{2} \mathrm{O}_{2}(0001) @ \mathrm{Li}_{2} \mathrm{CO}_{3}(011)$, interface. The thermodynamic barrier is found to be $0.53 \mathrm{eV}$ going from the peroxide to the carbonate; the blue dash lines represent the vacancy formation energies of bulk $\mathrm{Li}_{2} \mathrm{O}_{2}(+0.3 \mathrm{eV})$ and $\mathrm{Li}_{2} \mathrm{CO}_{3}(+\sim 1 \mathrm{eV})$ relative to the interface values.

Figure 7. Calculated IV curves from ATK using the RPBE exchange correlation functional with kpoint sampling $4 \times 6 \times 100$ at electron temperature of $300 \mathrm{~K}$ for a) Pristine $\mathrm{Li}_{2} \mathrm{O}_{2}$ and b) in the presence of a neutral lithium vacancy.

Figure 8. Calculated IV curves for a) pristine $\mathrm{Li}_{2} \mathrm{O}_{2}(0001) @ \mathrm{Li}_{2} \mathrm{CO}_{3}(011)$, b) with a neutral lithium vacancy at the $\mathrm{Li}_{2} \mathrm{O}_{2}(0001) v a c @ \mathrm{Li}_{2} \mathrm{CO}_{3}(011)$ interface.

Figure 9. Calculated polaron hopping paths using the NEB method along the intralayer in $X$ and $Y$ directions and interlayer along $Z$ direction in a $2 \times 2 \times 1 \mathrm{Li}_{2} \mathrm{O}_{2} @ \mathrm{Li}_{2} \mathrm{CO}_{3}$ interface supercell. Energies are obtained from RPBE $+U(\mathrm{U}=6 \mathrm{eV})$ method for $a)$ Electron and $b)$ Hole. 
Figure 1.
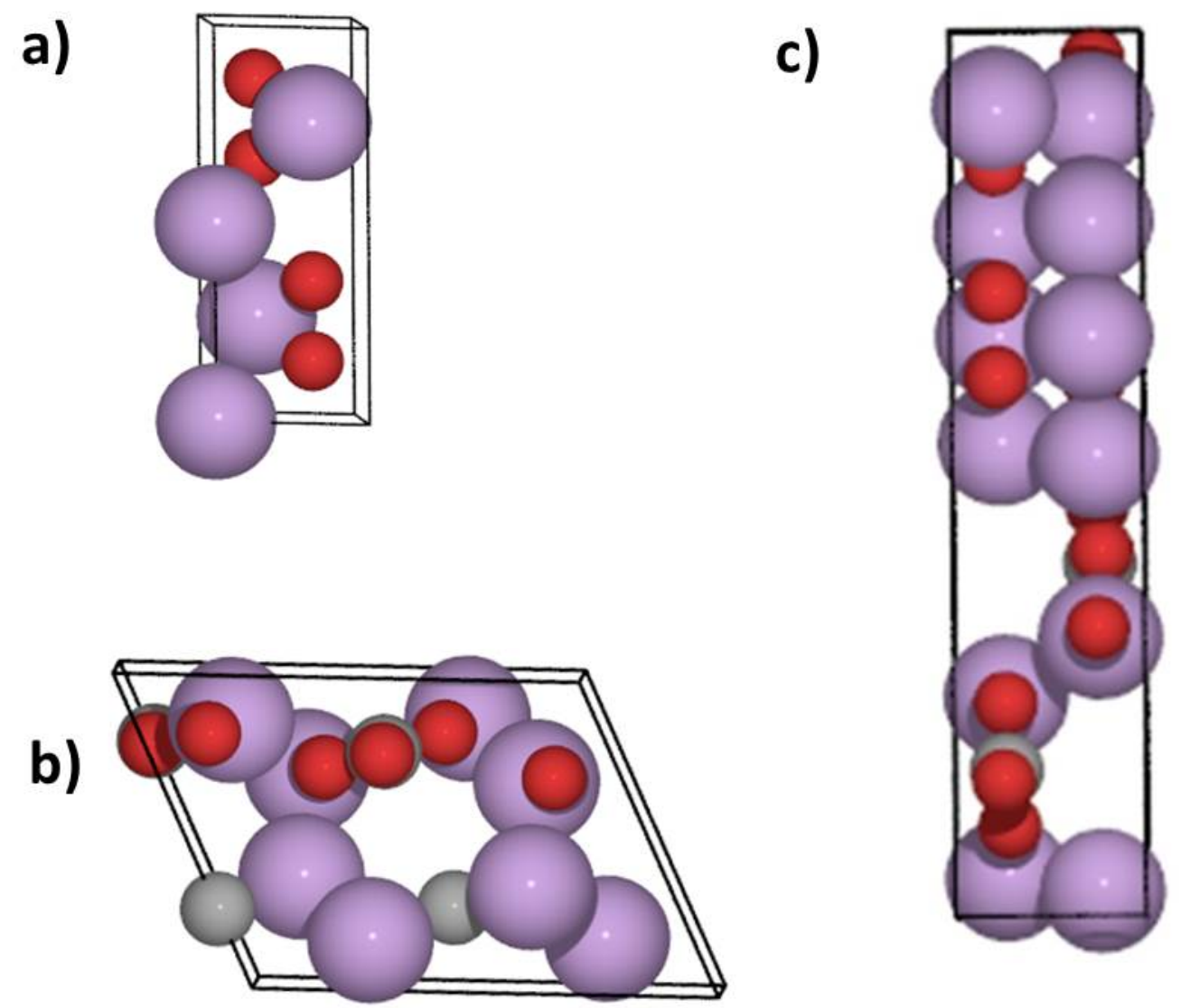
Figure 2.

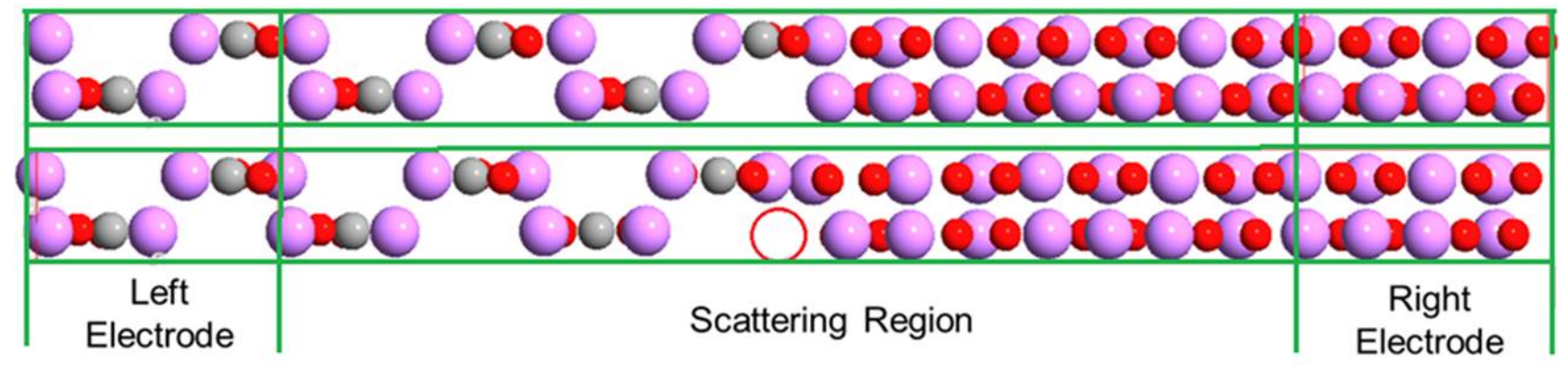


Figure 3.
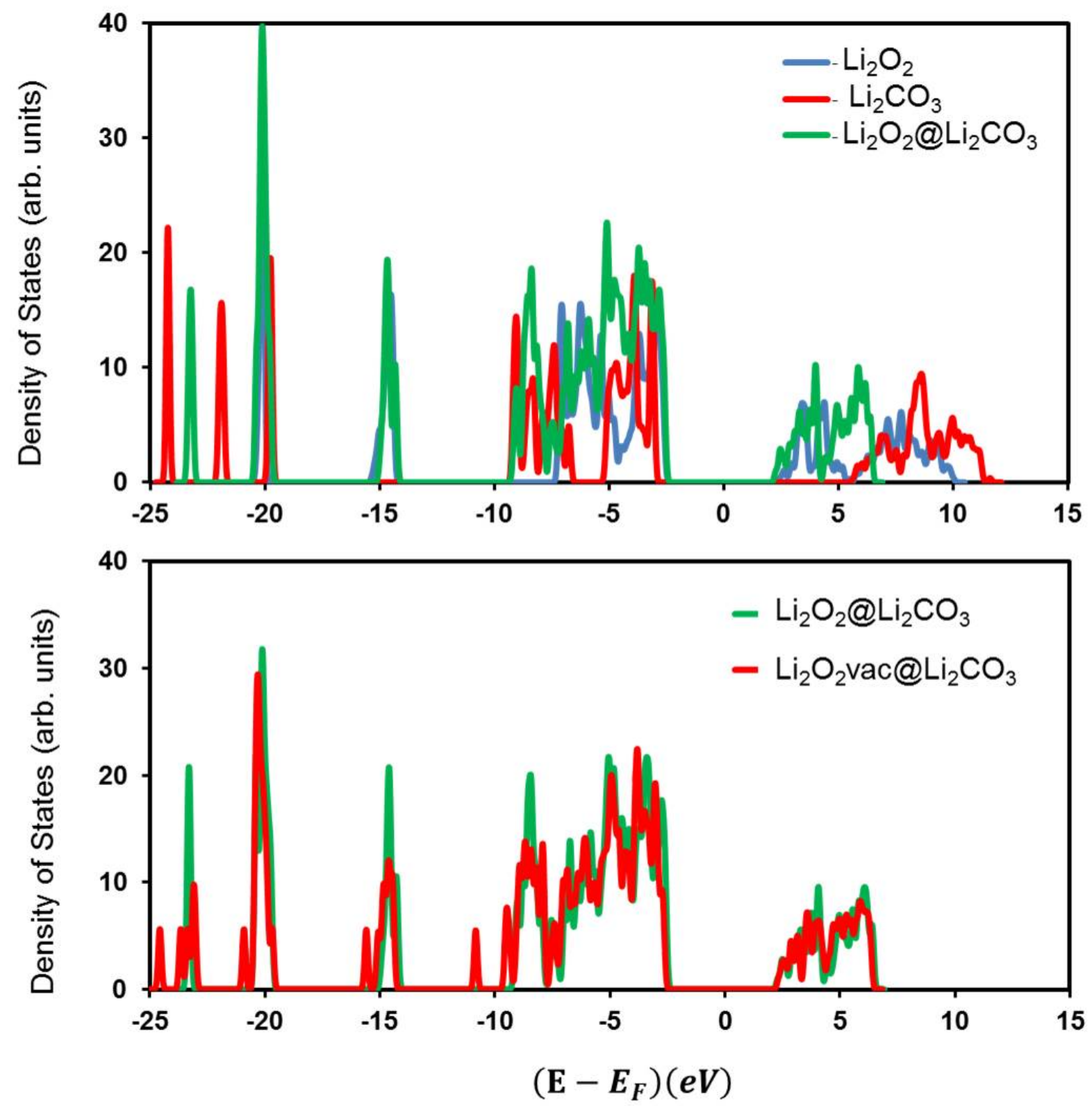
Figure 4.

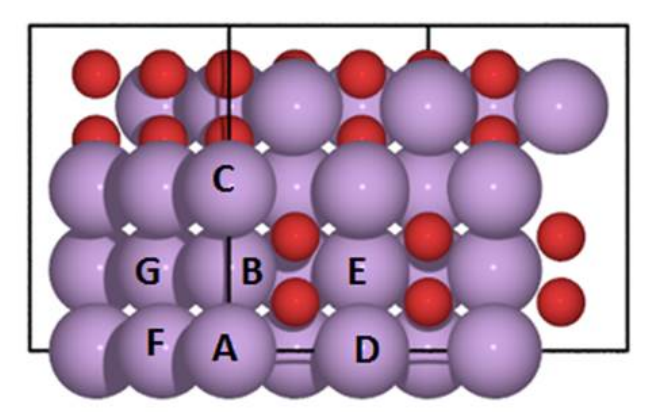

$I_{-x}$

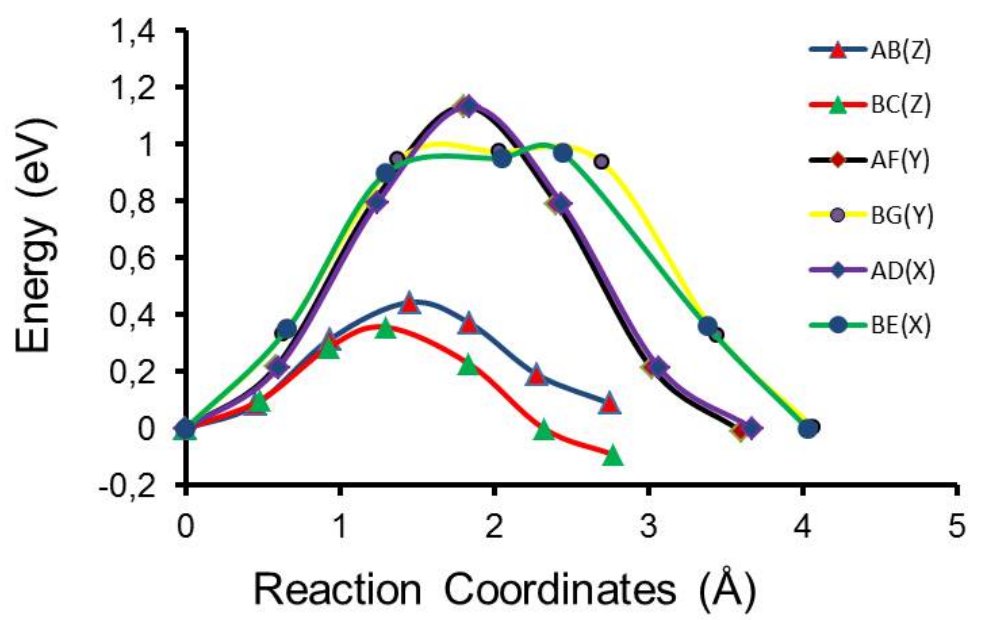


Figure 5.

Figure 5.
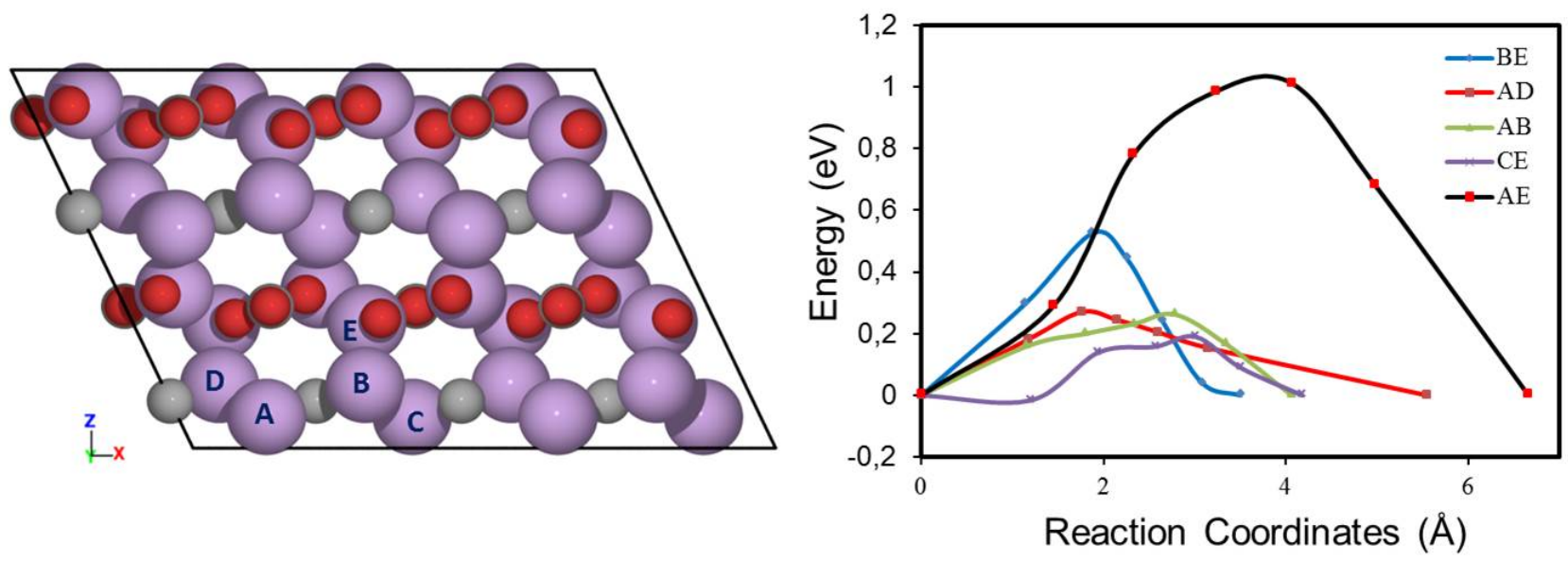
Figure 6.

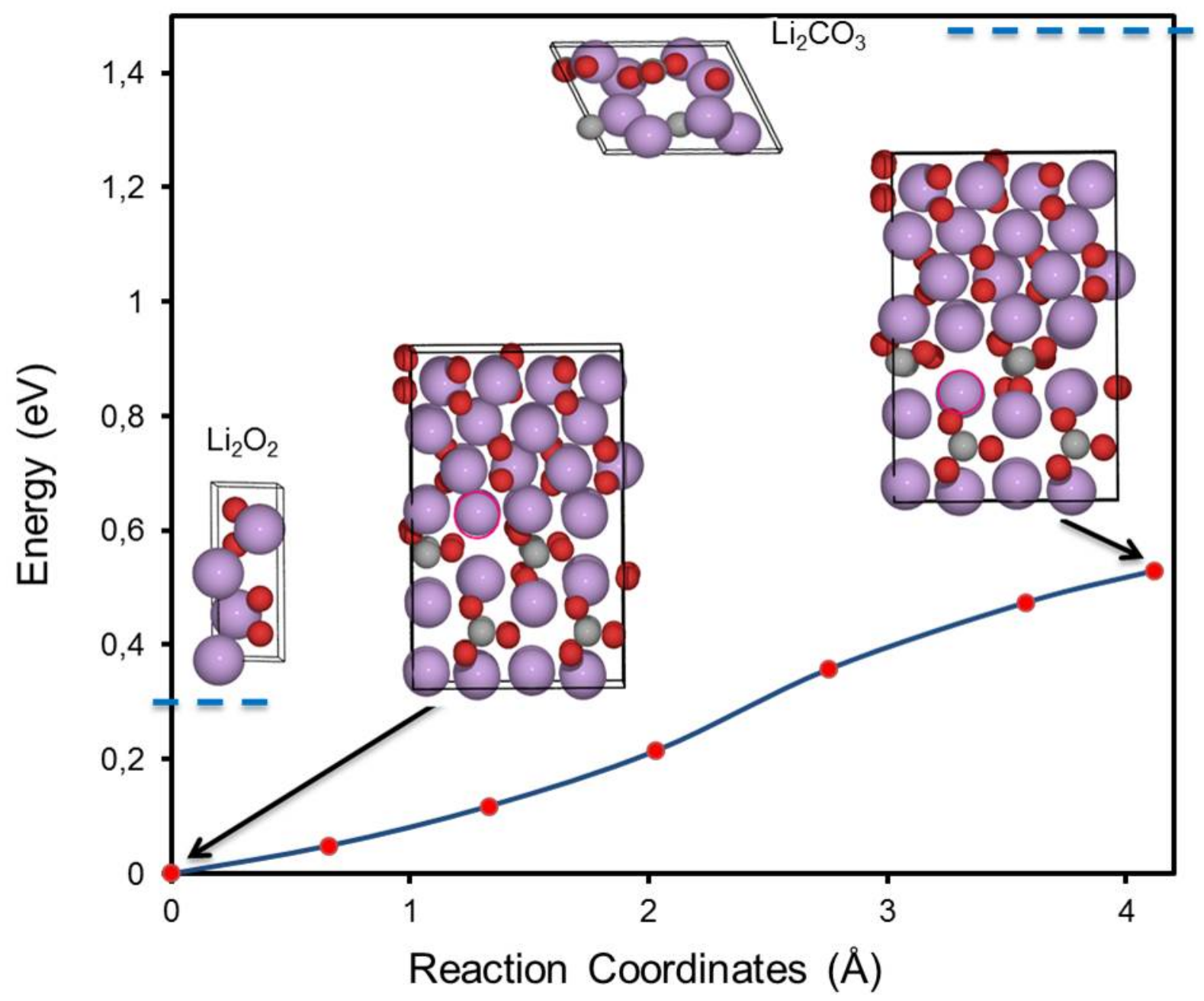


Figure 7.
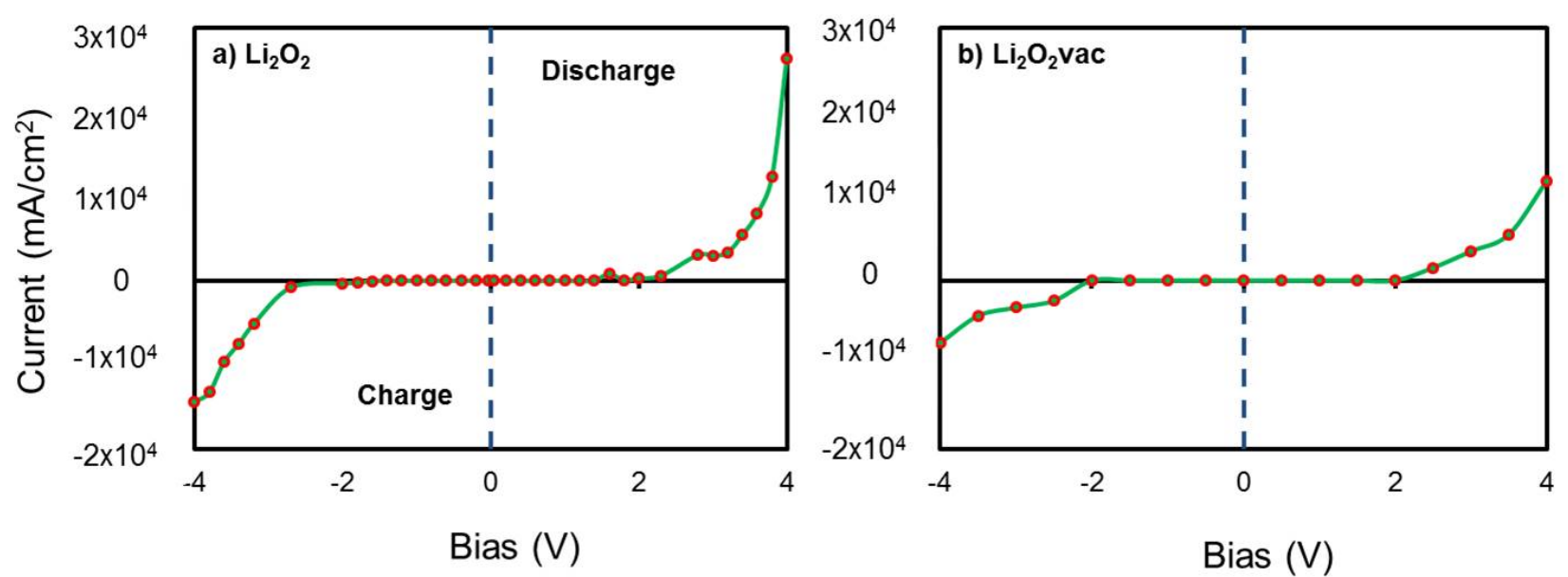
Figure 8.
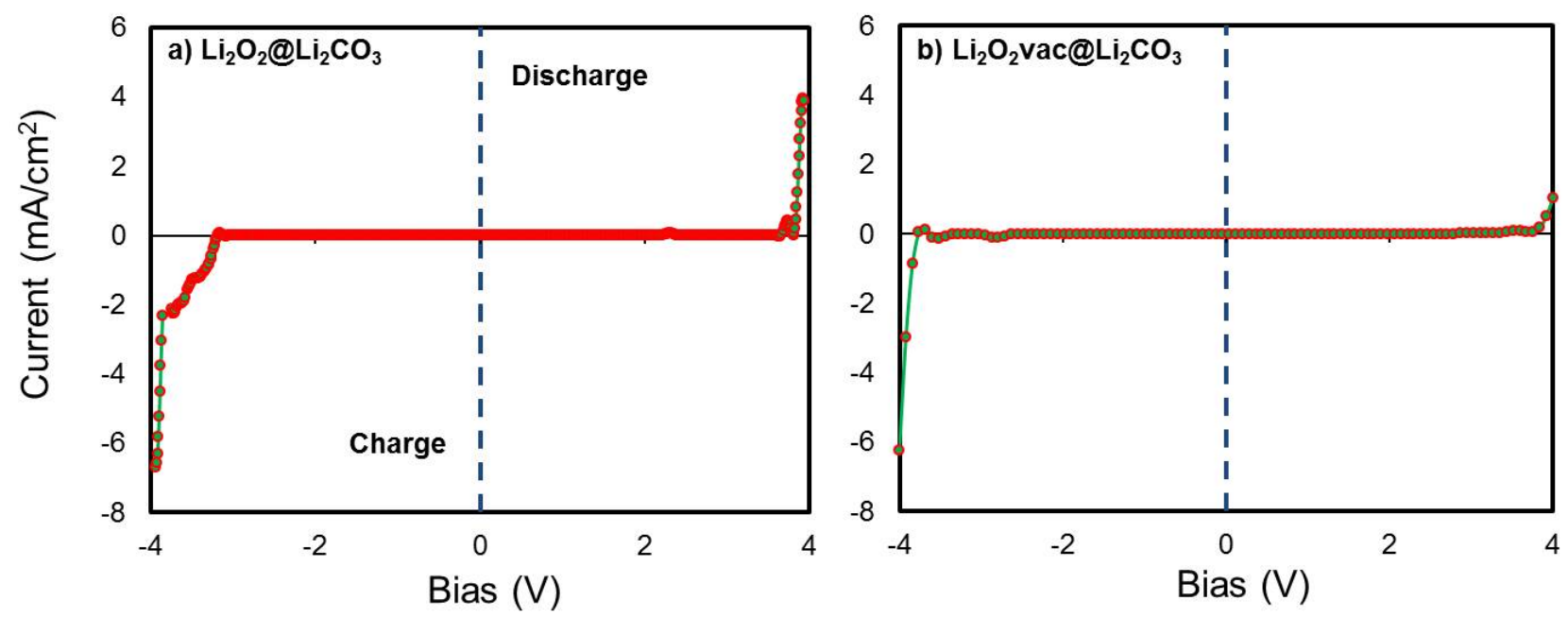
Figure 9.
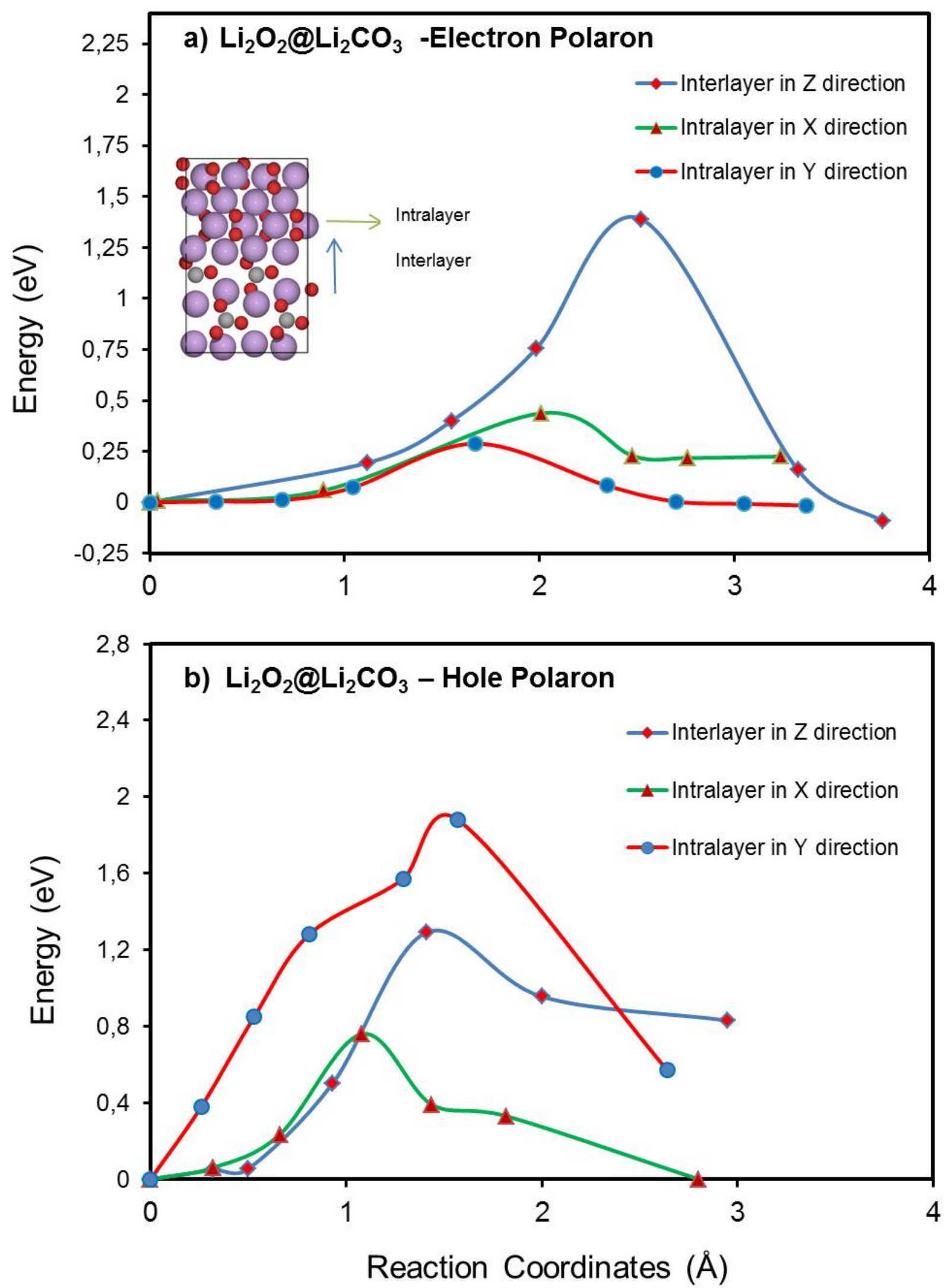